\title{
The Influence of Elastic Boundary on Modal Parameters of Thin Cylindrical Shell
}

\author{
Hui Li \\ School of Mechanical Engineering and Automation, Northeastern University, Shenyang, 110819, China. \\ Key Laboratory of Vibration and Control of Aero-Propulsion System Ministry of Education, Northeastern \\ University, Shenyang, 110819, China.
}

\author{
Haitao Luo \\ State Key Laboratory of Robotics, Shenyang Institute of Automation, Chinese Academy of Sciences (CAS), \\ Shenyang 110016, P.R. China.
}

\author{
Wei Sun and Bangchun Wen \\ School of Mechanical Engineering and Automation, Northeastern University, Shenyang, 110819, China. \\ Key Laboratory of Vibration and Control of Aero-Propulsion System Ministry of Education, Northeastern \\ University, Shenyang, 110819, China.
}

\section{(Received 24 June 2016; accepted 6 October 2017)}

This research combines theory with experiment to investigate the influence of an elastic boundary on modal parameters of a thin cylindrical shell (TCS). First, artificial stiffness method and finite element method (FEM) are employed to calculate natural frequencies and modal shapes of TCS under condition such that vibration characteristics of elastically supported shell can be roughly mastered. Then, the following measurements and identification techniques are used to get precise frequency, damping, and shape results: non-contact laser Doppler vibrometer and vibration shaker with excitation level being precisely controlled are used in the test system; "pre-experiment" is adopted to determine the required tightening torque as well as to verify whether or not the tested shell is under constraint boundary; and small-segment FFT processing technique is employed to accurately measure nature frequency, and laser rotating scanning technique is used to get shape results with high efficiency. Finally, based on the accurate measured data, the influences on natural frequencies, modal shapes, and damping ratios of TCS under elastic boundary are analysed and discussed. It can be found that an elastic boundary can significantly affect frequency and damping results, clearly reducing high order damping and decreasing natural frequencies of most modes. However, high order natural frequencies and mode shapes are still the same as the ones under the constraint condition, and the changing trend of natural frequencies with mode shapes is constant when the order of axial mode is $m=1$, which agrees well with the results calculated by artificial stiffness method and FEM.

\section{INTRODUCTION}

Thin cylindrical shell (TCS) has long been an important structural component due to its high stiffness to weight and strength to weight ratios, which is widely used in engineering fields, such as aircraft casings, pipes and ducts, rotary drums in granulators and aircraft engines. ${ }^{1,2}$ Modal parameters of TCS are mainly composed of natural frequencies, modal shapes, and damping ratio, and these parameters are the basis of further ${ }^{3-5}$ study on vibration characteristics of TCS, which are of great importance to theoretical modelling, response prediction, vibration reduction optimization, vibration mechanism research, structural damage identification etc.

In engineering practice, in order to reduce the vibration stress and suppress vibration fatigue of TCS, some vibration reduction techniques ${ }^{6,7}$ are used artificially. For example, friction damping snubber, metal rubber, elastic rubber and other material are gradually used to substitute traditional constraint or fixed boundary for elastic boundary, which can bear proper extrusion deformation to absorb and consume structural vibration energy. At present, the advantages of elastic boundary are recognized by an increasing number of engineers and researchers, ${ }^{8,9}$ and it has been approved to be an effective application in vibration control of the shell. There are also many shell structures running without under complete restraint boundary, or this may be called elastic boundary in a wider sense, especially when it is excited by the complex external loads, such as high-speed aerodynamic load and centrifugal load. Besides, TCS are often installed or connected by welding, riveting, and bolting, which can inevitably lead to loose or elastically restrained condition; ${ }^{10}$ thus, it is hard to ensure whether the shell is working under complete restraint boundary, and elastically supported shell structures are common in engineering field.

Currently, great efforts have been made to study vibration character of TCS under elastic boundary by scholars and researchers, and many encouraging research results have been obtained. For example, Forsberg ${ }^{11}$ studied the influence of boundary conditions on the modal characteristics of thin cylindrical shells. Total 16 possible sets of homogeneous boundary conditions were specified independently at each end of the shell, and these sets of conditions were discussed in detail. It has been found that even for long cylinders (length to radius ratio of 40 or more) the minimum natural frequency may differ 
by more than $50 \%$ depending upon whether the displacement of any point on the middle surface is in axial direction $u=0$ or the longitudinal stress resultant is $N_{x}=0$ at both ends. Koga ${ }^{12}$ studied the effects of boundary conditions on the free vibrations of TCS and a simple formula for the natural frequency was derived as an asymptotic solution for the eigenvalue problems of the breathing vibrations, whose accuracy was sequentially examined by a comparison with numerical solutions and experimental results. The results showed that the formula was accurate enough for engineering and it was applicable under any possible combinations of the boundary conditions for the simply supported, clamped, and free ends of the shell. Amabili and Dalpiaz ${ }^{13}$ studied the vibrations of circular cylindrical shells with non-axisymmetric mass distribution on elastic bed, and Rayleigh-Ritz method and Fourier series method were used to obtain natural frequencies and modal shapes of the shell. Loveday and Rogers ${ }^{14}$ analysed the free vibration of TCS with elastic boundary conditions by application of the exact solution of the Flugge shell theory equations of motion. The elastic boundaries were represented by distributed linear springs, and elastic boundary conditions could be simulated by varying the eight spring constants. Liang et al. ${ }^{15}$ studied stiffness optimization of TCS under elasticity boundary condition. The explicit formula of initial parameter solution of variable thickness shell was derived by transfer matrix method, and the optimization process was transformed into a constraint nonlinear solving process; thus, the objective function can be successfully obtained by the stepped reduction method. Zhou et al. ${ }^{16}$ used wave propagation method to solve the equations of motion of TCS under elastic-support boundary condition, and the elastic-support boundary condition was specified in terms of eight independent sets of distributed springs which have arbitrary stiffness values. Besides, the effects on natural frequencies of the restraining springs were also studied for a range of stiffness values and different geometrical characteristics of the shells, and it was found that the restraining stiffness can drastically affect frequency parameters of TCS. Sun ${ }^{17}$ studied free vibration and dynamic response of rotating TCS and employed three methods to analyse its natural characteristics under the different boundary condition, including Fourier series expansion method and wave propagation approach for TCS with classical boundary conditions, and Rayleigh-Ritz method with artificial spring for TCS with elastically constrained condition. Wu et al. ${ }^{18}$ studied vibration of a joined cylindricalspherical shell under elastic boundary by a domain decomposition method. The elastic-support boundary was regarded as a combination of distributed linear springs and can be treated as a special interface as well as the interface between two adjacent shell segments, and the theoretical results were compared with those derived by ANSYS to confirm the reliability and accuracy. Chen et al. ${ }^{19}$ studied vibration characteristics of cylindrical shell under complicated boundary conditions, such as elastic and non-uniform boundary conditions, and the exact solution was obtained by improved Fourier series method, but the calculated results were only compared with the finite element results rather than experimental results.

However, most of researches done by the above scholars and researchers are mainly based on theory or simulation; experimental studies on the influence of elastic boundary on modal parameters of TCS are still scarce. Besides, due to the complexity of the damping mechanism, it is difficult to obtain the
Table 1. Dimension parameters of TCS.

\begin{tabular}{|c|c|c|c|c|c|}
\hline Length & $\begin{array}{c}\text { Thick- } \\
\text { ness } \\
(\mathrm{mm})\end{array}$ & $\begin{array}{c}\text { Inter- } \\
\text { nal } \\
\text { radius } \\
(\mathrm{mm})\end{array}$ & $\begin{array}{c}\text { Exter- } \\
\text { nal } \\
\text { radius } \\
(\mathrm{mm})\end{array}$ & $\begin{array}{c}\text { Exten- } \\
\text { sion edge } \\
\text { radius } \\
(\mathrm{mm})\end{array}$ & $\begin{array}{c}\text { Exten- } \\
\text { sion edge } \\
\text { thickness } \\
(\mathrm{mm})\end{array}$ \\
\hline 95 & 2 & 142 & 144 & 150 & 3 \\
\hline
\end{tabular}

Table 2. Material parameters of TCS.

\begin{tabular}{|c|c|c|c|}
\hline Name & $\begin{array}{c}\text { Elastic } \\
\text { modulus (Gpa) }\end{array}$ & $\begin{array}{c}\text { Poisson } \\
\text { ratio }\end{array}$ & $\begin{array}{c}\text { Density } \\
\left(\mathrm{kg} / \mathrm{m}^{3}\right)\end{array}$ \\
\hline Structural steel & 212 & 0.3 & 7850 \\
\hline
\end{tabular}

reliable damping parameters of the shell-only-based theoretical model, let alone analysing the related influence on damping parameters. Therefore, it is necessary to combine theory with experiment to investigate the influence of elastic boundary on modal parameters of TCS.

This research has investigated the influence of elastic boundary on modal parameters of TCS. First, in Section 2 artificial stiffness method (ASM) and finite element method (FEM) are employed to calculate natural frequencies and modal shapes of TCS under conditions such that vibration characteristics of elastically supported shell can be roughly mastered. Then, experiment system is set up to accurately measure modal parameters of TCS, and the corresponding test procedures and identification techniques suitable for elastically supported shell are proposed in Section 3. Finally, in Section 4, based on the accurate measured data, the influence on natural frequencies, modal shapes, and damping ratios of TCS under elastic boundary are analysed and discussed in detail. This research can provide dynamic modelling service for TCS under complex boundary condition, provide experimental data for effective selection of boundary parameters in the theoretical model, and also provide an important reference for diagnosis of vibration fault of elastically supported shell.

\section{THEORETICAL ANALYSIS OF NATURE FREQUENCY AND MODAL SHAPE OF TCS UNDER ELASTIC BOUNDARY}

\subsection{Research Object and Simulation of Elastic Boundary}

The TCS studied in this research is shown in Fig. 1 and its dimension and material parameters are listed in Table 1 and Table 2, respectively. There is an extension edge with $150 \mathrm{~mm}$ external radius and $3 \mathrm{~mm}$ thickness on this shell which is machined to be clamped by a clamping-ring with eight M8 bolts, so that it can be of certain that the shell be restricted under fixed-free boundary (or called under constraint boundary with one end free). Then, we can simulate different elastic boundary conditions by filling rubber ring of different thickness into the position between the clamping-ring and extension edge and tightening M8 bolts with certain tightening torque, as seen in Fig. 1. For example, we can fill $1 \mathrm{~mm}, 2 \mathrm{~mm}$, and $3 \mathrm{~mm}$ rubber rings to simulate the various types of elastic boundaries, and the related material parameters of ZN33 elastomer used in this research are listed in Table 3.

\subsection{Artificial Stiffness Method}

In practice, elastic boundary conditions commonly exist in the connection positions of TCS and complete constraint 
Table 3. Material parameters of elastic rubber.

\begin{tabular}{|c|c|c|c|}
\hline Name & $\begin{array}{c}\text { Elastic } \\
\text { modulus (Gpa) }\end{array}$ & $\begin{array}{c}\text { Poisson } \\
\text { ratio }\end{array}$ & $\begin{array}{c}\text { Density } \\
\left(\mathrm{kg} / \mathrm{m}^{3}\right)\end{array}$ \\
\hline ZN33 elastomer & 2.68 & 0.498 & 999 \\
\hline
\end{tabular}

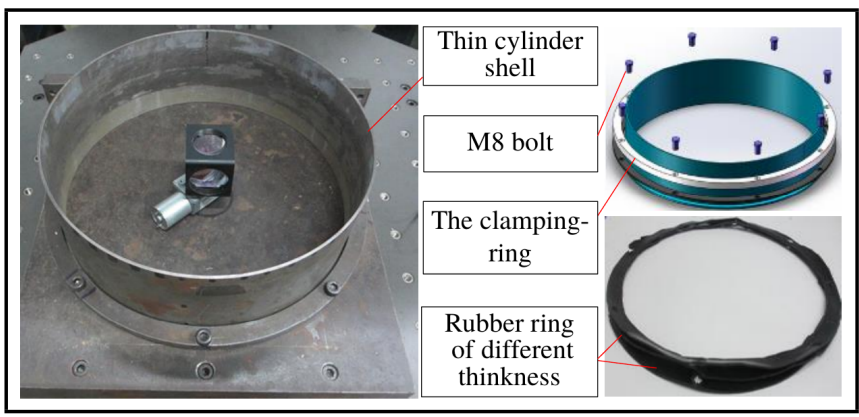

Figure 1. TCS and simulation of elastic boundary using rubber ring.

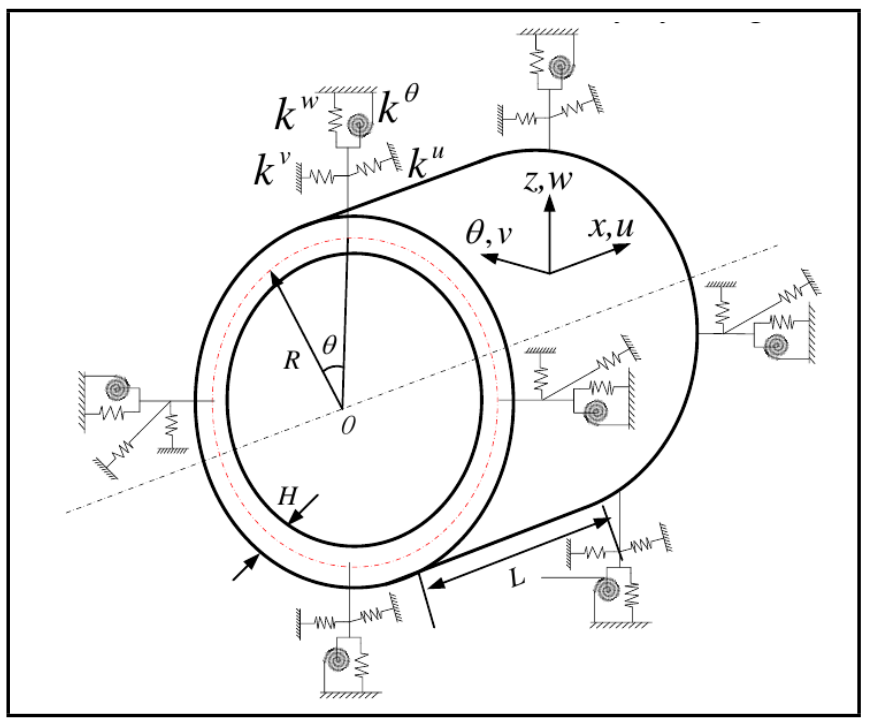

Figure 2. Dynamic model of TCS under elastic boundary based on ASM.

boundary is hard to reach. Therefore, Artificial stiffness method is proposed to calculate the natural frequency of thin cylindrical shell under elastic boundary, and their stiffness can be modified to simulate the actual constraint effect, which assumes some virtual springs are on two sides of TCS. ${ }^{20-22}$ Figure 2 gives the dynamic model of TCS under elastic boundary, whose length, radius, and thickness is $L, R$, and $H$. First, the assumptions that the TCS studied in this research can meet isotropic and homogeneity hypothesis and the influences of shear stress as well as boundary damping are ignored. Then, the curvilinear coordinates system $o-x \theta z$ is used in this model by taking the generatrix and parallel direction of TCS as two main directions, any point on the middle surface of the shell can be described by $(x, \theta)$, where $x$ is the generatrix length from the vertex to the point $(x, \theta)$ and $\theta$ is the corresponding rotation angle. Besides, $u, v$ and $w$ is the displacement of any point on the middle surface in the $x, \theta, z$ direction, and $k^{u}, k^{v}, k^{w}$ is the support stiffness in $u, v$ and $w$ direction while $k^{\theta}$ is the rotation stiffness.

In above method, boundary damping is ignored while the influence of the artificial spring is taken into consideration, and different support stiffnesses of artificial spring are used to simulate different elastic boundaries by changing the magnitude of $k^{u}, k^{v}, k^{w}, k^{\theta}$. According to the linear shell theory and small deformation theory, the strain equation in the middle surface of the shell can be described as:

$$
\left\{\begin{array}{l}
\varepsilon_{x x} \\
\varepsilon_{\theta \theta} \\
\gamma_{x \theta}
\end{array}\right\}_{(0)}=\left[\begin{array}{ccc}
\frac{\partial}{\partial x} & 0 & 0 \\
0 & \frac{1}{R} \frac{\partial}{\partial \theta} & \frac{1}{R} \\
\frac{1}{R} \frac{\partial}{\partial \theta} & \frac{\partial}{\partial x} & 0
\end{array}\right]\left\{\begin{array}{c}
u \\
v \\
w
\end{array}\right\} ;
$$

where subscript $(0)$ refers to the middle surface. Based on Donnell-Mushtari shell theory, the curvature coefficient $\kappa_{x}, \kappa_{\theta}$ and twist coefficient $\chi_{x \theta}$ at the middle surface are:

$$
\left\{\begin{array}{c}
\kappa_{x} \\
\kappa_{\theta} \\
\chi_{x \theta}
\end{array}\right\}=\left[\begin{array}{ccc}
0 & 0 & -\frac{\partial^{2}}{\partial x^{2}} \\
0 & \frac{1}{R^{2}} \frac{\partial}{\partial \theta} & -\frac{1}{R^{2}} \frac{\partial^{2}}{\partial \theta^{2}} \\
0 & \frac{1}{R} \frac{\partial}{\partial x} & -\frac{2}{R} \frac{\partial^{2}}{\partial x \partial \theta}
\end{array}\right]\left\{\begin{array}{c}
u \\
v \\
w
\end{array}\right\} .
$$

Because the deformation of the shell is closely related with the displacement of middle surface, the strain at any point in the shell can be written in terms of strain, curvature, and twist coefficients in the middle surface and it can be described as:

$$
\left\{\begin{array}{c}
\varepsilon_{x} \\
\varepsilon_{\theta} \\
\gamma_{x \theta}
\end{array}\right\}=\left\{\begin{array}{c}
\varepsilon_{x x} \\
\varepsilon_{\theta \theta} \\
\gamma_{x \theta}
\end{array}\right\}+z\left\{\begin{array}{c}
\kappa_{x} \\
\kappa_{\theta} \\
\chi_{x \theta}
\end{array}\right\}
$$

where $z$ is the distance from any point in the shell to the middle surface.

The strain-displacement relations at any point in the shell can be derived from above equation as:

$$
\begin{aligned}
\varepsilon_{x} & =\frac{\partial u}{\partial x}-z \frac{\partial^{2} w}{\partial x^{2}} \\
\varepsilon_{\theta} & =\frac{1}{R}\left(\frac{\partial v}{\partial \theta}+w\right)-z \frac{1}{R^{2}} \frac{\partial^{2} w}{\partial \theta^{2}}+z \frac{1}{R^{2}} \frac{\partial v}{\partial \theta} \\
\gamma_{x \theta} & =\frac{\partial v}{\partial x}+\frac{1}{R} \frac{\partial u}{\partial \theta}-z \frac{2}{R} \frac{\partial^{2} w}{\partial x \partial \theta}+z \frac{1}{R} \frac{\partial v}{\partial x} .
\end{aligned}
$$

The physical equation of the shell can be expressed as:

$$
\begin{aligned}
\sigma_{x} & =\frac{E}{1-\mu^{2}}\left(\varepsilon_{x}+\mu \varepsilon_{\theta}\right) ; \\
\sigma_{\theta} & =\frac{E}{1-\mu^{2}}\left(\varepsilon_{\theta}+\mu \varepsilon_{x}\right) ; \\
\tau_{x \theta} & =G \gamma_{x \theta} ;
\end{aligned}
$$

where $E$ is Young's modulus and $\mu$ is Poisson's ratio.

The expression of kinetic energy of TCS can be described as:

$$
T=\frac{\rho H L}{2} \int_{0}^{2 \pi} \int_{0}^{1}\left(\dot{u}^{2}+\dot{v}^{2}+\dot{w}^{2}\right) R \mathrm{~d} \theta \mathrm{d} \xi ;
$$

where $\xi=x L,(\cdot)=\partial / \partial t$ is the partial derivative of time.

Taking bending and shear deformation of shell into consideration, the potential energy of the shell can be expressed as:

$$
U_{\varepsilon}=\frac{H L}{2} \int_{0}^{1} \int_{0}^{2 \pi}\left(\sigma_{x} \varepsilon_{x}+\sigma_{\theta} \varepsilon_{\theta}+\tau_{x \theta} \gamma_{x \theta}\right) R \mathrm{~d} \theta \mathrm{d} \xi .
$$

Simplifying Eq. (7), we can deduce that:

$U_{\varepsilon}=\frac{L H}{2} \int_{0}^{1} \int_{0}^{2 \pi}\left\{\begin{array}{l}\frac{E}{1-\mu^{2}}\left[\left(\varepsilon_{x}\right)^{2}+\left(\varepsilon_{\theta}\right)^{2}\right]+ \\ \frac{2 \mu E}{1-\mu^{2}} \varepsilon_{x} \varepsilon_{\theta}+G\left(\gamma_{x}\right)^{2}\end{array}\right\} R \mathrm{~d} \theta \mathrm{d} \xi$ 
where $G=\frac{E}{2(1+\mu)}$ is the shear modulus.

Because the studied TCS is under free-clamped boundary condition, we can employ ASM to place artificial spring on two sides of the shell, as shown in Fig. 2. It should be noted that in this method, when the support stiffness $k_{0}^{u}=k_{0}^{v}=k_{0}^{w}=$ $k_{0}^{\theta} \geq 10^{8}$ and $k_{1}^{u}=k_{1}^{v}=k_{1}^{w}=k_{1}^{\theta}=0$, it represents the freeclamped boundary condition, and the subscript 0 denotes the fixed end while the subscript 1 denotes the free end of the shell. When support stiffness $k_{0}^{u}=k_{0}^{v}=k_{0}^{w}=k_{0}^{\theta}=10^{5} \sim 10^{8}$ and $k_{1}^{u}=k_{1}^{v}=k_{1}^{w}=k_{1}^{\theta}=0$, it represents the elastic-free boundary condition. Therefore, by changing the magnitude of $k_{1}^{u}, k_{1}^{v}, k_{1}^{w}, k_{1}^{\theta}$, we can simulate different elastic boundaries, and the related elastic potential energy of artificial spring under such boundary can be described as:

$$
\begin{gathered}
U_{s p}=\frac{1}{2} \int_{0}^{2 \pi}\left\{k_{0}^{u}[u(0, \theta, t)]^{2}+k_{0}^{v}[v(0, \theta, t)]^{2}\right. \\
\left.+k_{0}^{w}[w(0, \theta, t)]^{2} k_{0}^{\theta} \frac{1}{L^{2}}\left[\frac{\partial w(0, \theta, t)}{\partial \xi}\right]^{2}\right\} R \mathrm{~d} \theta \\
\quad+\frac{1}{2} \int_{0}^{2 \pi}\left\{k_{1}^{u}[u(1, \theta, t)]^{2}+k_{1}^{v}[v(1, \theta, t)]^{2}\right. \\
\left.+k_{1}^{w}[w(1, \theta, t)]^{2} k_{1}^{\theta} \frac{1}{L^{2}}\left[\frac{\partial w(1, \theta, t)}{\partial \xi}\right]^{2}\right\} R \mathrm{~d} \theta .
\end{gathered}
$$

Next, we use orthogonal polynomials to assume shape functions of the shell, and the Rayleigh-Ritz method is employed to calculate the natural characteristics of TCS under elastic boundary. According to Rayleigh-Ritz method, we can assume that the vibration displacement of the shell has the following forms:

$$
\left\{\begin{array}{l}
u=e^{-j \omega t} \cos n \theta U(\xi) \\
v=e^{-j \omega t} \sin n \theta V(\xi) \\
w=e^{-j \omega t} \cos n \theta W(\xi)
\end{array} .\right.
$$

Here, $\omega$ is the natural frequency, $n$ is the circumferential waves of the TCS , and $U(\xi), V(\xi), W(\xi)$ are modal shape functions in $x, \theta$ and $z$ direction, respectively.

Then transforming $U(\xi), V(\xi)$, and $W(\xi)$ into polynomial forms, we can have the following expression:

$$
\left\{\begin{array}{rl}
U(\xi) & =\sum_{m=1}^{N T} a_{m} \varphi^{u}(\xi) \\
V(\xi) & =\sum_{m=1}^{N T} b_{m} \varphi^{v}(\xi) \\
W(\xi) & =\sum_{m=1}^{N T} c_{m} \varphi^{w}(\xi)
\end{array} .\right.
$$

Here, $a_{m}, b_{m}$, and $c_{m}$ are shape coefficients, $\varphi^{u}(\xi), \varphi^{v}(\xi)$, and $\varphi^{w}(\xi)$ are orthogonal polynomials, which should satisfy the geometrical boundary conditions.

Construct the following equation:

$$
\begin{aligned}
\psi_{2}^{p}(\xi) & =\left(\xi-B_{2}\right) \psi_{1}^{p}(\xi) ; \\
\psi_{k}^{p}(\xi) & =\left(\xi-B_{k}\right) \psi_{k-1}^{p}(\xi)-C_{k} \psi_{k-2}^{p}(\xi), k 2 ;
\end{aligned}
$$

where $B_{k}=\frac{\int_{0}^{\xi} \xi \psi_{k-1}^{p}{ }^{2}(\xi) \mathrm{d} \xi}{\int_{0}^{\xi} \psi_{k-1}^{p}{ }^{2}(\xi) \mathrm{d} \xi}, C_{k}=\frac{\int_{0}^{\xi} \xi \psi_{k-1}^{p}{ }^{2}(\xi) \psi_{k-2}^{p}{ }^{2}(\xi) \mathrm{d} \xi}{\int_{0}^{\xi} \psi_{k-2}^{p}{ }^{2}(\xi) \mathrm{d} \xi}$.

Define the 2-norm of $\psi(\xi)$ as the following:

$$
\left\|\psi_{k}(\xi)\right\|_{2}=\sqrt{\int_{0}^{\xi}\left[\psi_{k}^{p}(\xi)\right]^{2} \mathrm{~d} \xi} ;(p=u, v, w) ;
$$

Define $\varphi_{m}^{p}(\xi)(p=u, v, w)$ as the orthogonal basis, which can be expressed as:

$$
\varphi_{m}^{p}(\xi)=\frac{\psi_{k}^{p}(\xi)}{\left\|\psi_{k}^{p}(\xi)\right\|_{2}}(p=u, v, w)
$$

The orthogonal basis function needs to satisfy the following relation:

$$
\int_{0}^{1} \varphi_{k}^{p}(\xi) \varphi_{l}^{p}(\xi) \mathrm{d} \xi=\delta_{k l},(p=u, v, w) ;
$$

where $\delta_{k l}$ is Kronecker function.

Substituting Eq. (10) into Eq. (6), and further simplifying the equation, we can obtain the expression of kinetic energy of the shell:

$$
T=-\frac{\pi \rho H R L \omega^{2}}{2} e^{-2 j \omega t} \int_{0}^{1}\left[U^{2}+V^{2}+W^{2}\right] \mathrm{d} \xi .
$$

Substituting Eq. (10) into Eq. (7), and further simplifying the equation, we can obtain the potential energy expression of the shell:

$$
\begin{aligned}
& U_{\varepsilon}=\frac{L E H \pi}{2 R\left(1-\mu^{2}\right)} e^{-2 j \omega t} \int_{0}^{1}\left(\begin{array}{l}
\left(\frac{H^{2} n^{4}}{12 R^{2}}+1\right) W^{2}+ \\
\frac{n^{2} H^{2}}{12 R^{2}} V_{s}^{2}+\left(\frac{n^{3} H^{2}}{6 R^{2}}+2 n\right) V_{s} W
\end{array}\right. \\
& +(1-\mu)\left(\begin{array}{l}
\frac{n^{2}}{2} U_{s}^{2}+\frac{n H^{2}}{6 L^{2}} W^{\prime} V^{\prime}{ }_{s}+\left(\frac{R^{2}}{2 L^{2}}+\frac{H^{2}}{24 L^{2}}\right) V_{s}^{\prime 2} \\
+\frac{n^{2} H^{2}}{6 L^{2}} W^{\prime 2}-n \frac{R}{L} V_{s}^{\prime} U_{s}
\end{array}\right) .
\end{aligned}
$$

Substituting Eq. (10) into Eq. (9), and further simplifying the equation, the elastic potential energy expression of the artificial spring can be expressed as:

$$
\begin{aligned}
& U_{s p}^{*}=\left\{\begin{array}{l}
\tilde{k}_{0}^{u}[U(0)]^{2}+\tilde{k}_{0}^{v}[V(0)]^{2}+ \\
\tilde{k}_{0}^{w}[W(0)]^{2}+\tilde{k}_{0}^{\theta}\left[\frac{\partial W(0)}{\partial \xi}\right]^{2}
\end{array}\right\} \\
& +\left\{\begin{array}{l}
\tilde{k}_{1}^{u}[U(1)]^{2}+\tilde{k}_{1}^{v}[V(1)]^{2}+ \\
\tilde{k}_{1}^{w}[W(1)]^{2}+\tilde{k}_{1}^{\theta}\left[\frac{\partial W(1)}{\partial \xi}\right]^{2}
\end{array}\right\} .
\end{aligned}
$$

Here, $\tilde{k}_{i}^{u}, \tilde{k}_{i}^{v}, \tilde{k}_{i}^{w}$, and $\tilde{k}_{i}^{\theta}$ are dimensionless stiffness, and these parameters can be expressed as follow:

$$
\begin{array}{ll}
\tilde{k}_{i}^{u}=\frac{R^{2}\left(1-\mu^{2}\right)}{E H L} k_{i}^{u} ; & \tilde{k}_{i}^{v}=\frac{R^{2}\left(1-\mu^{2}\right)}{E H L} k_{i}^{v} ; \\
\tilde{k}_{i}^{w}=\frac{R^{2}\left(1-\mu^{2}\right)}{E H L} k_{i}^{w} ; & \tilde{k}_{i}^{\theta}=\frac{R^{2}\left(1-\mu^{2}\right)}{E H L^{3}} k_{i}^{\theta} ;
\end{array}
$$

where $i=0,1$, and 0 refers to the fixed end while 1 refers to the free end.

According to Rayleigh-Ritz method, the dimensionless frequency of TCS can be written as follows

$$
\left(\omega^{*}\right)^{2}=\frac{U^{*}+U_{s p}^{*}}{T^{*}}
$$

Here,

$$
\omega^{*}=\omega R \sqrt{\rho\left(1-\mu^{2}\right) / E} ;
$$




$$
\begin{gathered}
T^{*}=\int_{0}^{1}\left[U^{2}+V^{2}+W^{2}\right] \mathrm{d} \xi \\
U^{*}=\int_{0}^{1}\left(\left(\frac{H^{2} n^{4}}{12 R^{2}}+1\right) W^{2}+\frac{n^{2} H^{2}}{12 R^{2}} V_{s}^{2}\right. \\
+\left(\frac{n^{3} H^{2}}{6 R^{2}}+2 n\right) V_{s} W+\frac{R^{2}}{L^{2}} U^{\prime 2} s \\
\left.\left.+\frac{R^{2}}{2 L^{2}}+\frac{H^{2}}{24 L^{2}}\right) V_{s}^{2}+\frac{n^{2}}{6 L^{2}} W^{\prime} W^{\prime 2}-{ }^{2}+\frac{R}{L} V_{s}^{\prime} U_{s}\right) \\
+2 \mu \frac{R}{L} U^{\prime}{ }_{s} W+\frac{n^{2}}{12 L^{4}} U_{s}^{2} W^{\prime \prime 2}-\frac{\mu n^{2} H^{2}}{6 L^{2}} W^{\prime \prime} W \\
\left.\quad-\frac{\mu n H^{2}}{6 L^{2}} W^{\prime \prime} V_{s}+2 \mu n \frac{R}{L} U^{\prime}{ }_{s} V_{s}\right) \mathrm{d} \xi
\end{gathered}
$$

Taking the partial of shape coefficients $a_{m}, b_{m}$, and $c_{m}$ which are related to $U(\xi), V(\xi)$, and $W(\xi)$ in Eq. (11), we can have the characteristic equation in Eq. (25), and bring different $k_{0}^{u}, k_{0}^{v}, k_{0}^{w}, k_{0}^{\theta}$ and $k_{1}^{u}, k_{1}^{v}, k_{1}^{w}, k_{1}^{\theta}$ into this equation, we can calculate the natural frequency of TCS under elastic boundary by ASM.

$$
\begin{aligned}
& \frac{\partial \omega^{*}}{\partial a_{m}}=\frac{\partial \omega^{*}}{\partial b_{m}}=\frac{\partial \omega^{*}}{\partial c_{m}}=0 \\
& {\left[\mathbf{K}+\mathbf{K}_{s p r}-\omega^{* 2} \mathbf{M}\right] \mathbf{X}=0} \\
& \mathbf{K}=\left[\begin{array}{ccc}
k^{a a} & k^{a b} & k^{a c} \\
k^{b a} & k^{b b} & k^{b c} \\
k^{c a} & k^{c b} & k^{c c}
\end{array}\right] \\
& \mathbf{K}_{s p}=\left[\begin{array}{ccc}
k s^{a a} & & \\
& k s^{b b} & \\
& & k s^{c c}
\end{array}\right] \text {; } \\
& \mathbf{M}=\left[\begin{array}{ccc}
M^{a a} & & \\
& M^{b b} & \\
& & M^{c c}
\end{array}\right] \text {; }
\end{aligned}
$$

Here, $\mathbf{X}=\left\{\begin{array}{lll}a_{m} & b_{m} & c_{m}\end{array}\right\}^{T}$ is Ritz vector, $\mathbf{K}, \mathbf{K}_{s p}$, and $\mathbf{M}$ are stiffness matrix, artificial spring stiffness matrix, and mass matrix, respectively, and the expression of the elements in the stiffness matrix, artificial spring stiffness matrix, and mass matrix can be seen in Appendix A, B, C. Besides, it should be noted that the numbers of row and column of $\mathbf{K}, \mathbf{K}_{s p}$, and $\mathbf{M}$ are $3 N T \times 3 N T$, where $N T$ is the number of orthogonal polynomials. In this research in order to ensure calculation accuracy, we set $N T=7(3 N T=21)$, so the numbers of row and column of $\mathbf{K}, \mathbf{K}_{s p}$, and $\mathbf{M}$ are $21 \times 21$.

\subsection{Finite Element Method (FEM)}

In this section, different thickness of rubber rings are used to simulate various types of elastic boundaries, and finite element model of TCS under elastic boundary is established, which is used to calculate the natural frequencies and modal shapes, so

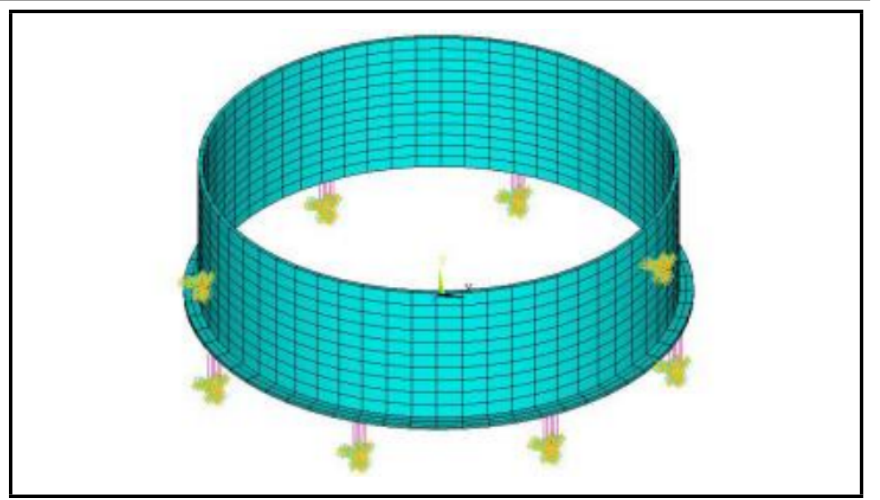

Figure 3. Finite element model of TCS under elastic boundary condition.

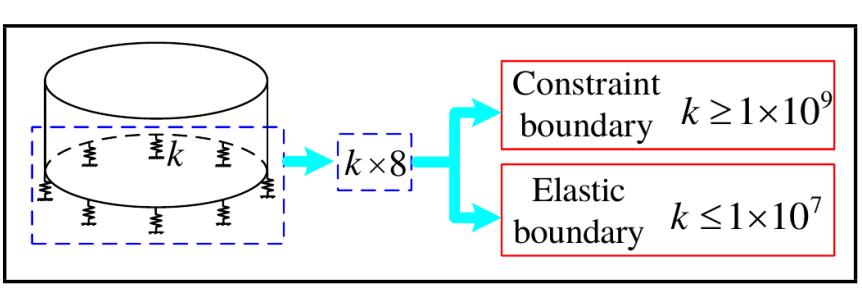

Figure 4. Spring stiffnesses of finite element model of TCS in the simulation of the constrained boundary and elastic boundary.

that vibration characteristics of elastically supported shell can be roughly mastered.

Finite element model of TCS under elastic boundary condition is established with Ansys Parametric Design Language (APDL) in ANSYS software, as seen in Fig. 3. SOLID186 element is used to create the model of the shell which consists of 6480 nodes and 960 elements, and MATRIX27 element is used as spring element to simulate different thickness of rubber rings in the elastic boundary by adjusting stiffness value in the $X, Y, Z$ directions, which consists of a total of 8 spring elements and 80 nodes.

Eight spring elements with stiffness value of $k=1 \times 10^{7}$, $k=1 \times 10^{6}, k=1 \times 10^{5}$ are used to simulate the elastically supported shell with the thicknesses of $1 \mathrm{~mm}, 2 \mathrm{~mm}$, and $3 \mathrm{~mm}$, as seen in Fig. 4 named as elastic boundary I, elastic boundary II, and elastic boundary III, respectively, and then the natural frequencies and modal shapes can be calculated by Block Lanczos method. The stiffness value of the eight spring elements is set to $k=1 \times 10^{9}$, so as to simulate the free-clamped boundary condition (also see in Fig. 4), and the same method is employed to calculate the frequency and shape parameters of TCS under constraint boundary.

\subsection{Theoretical Analysis Results and Conclusion}

In the above section, ASM and FEM are used to establish the theoretical model of elastically supported shell. In this section, the theoretical analysis results are analysed and discussed in detail.

First, set stiffness value of eight spring elements to $k=$ $1 \times 10^{9}, k=1 \times 10^{7}, k=1 \times 10^{6}, k=1 \times 10^{5}$ in the $X, Y, Z$ directions, and finish the calculation work of frequency and shape parameters of TCS under constraint boundary as well as elastic boundary with different thickness of rubber ring. The first eight natural frequencies of modal shapes calculated by FEM are listed in Table 4 and Table 5. Then, set the support stiffness as $k_{u}=k_{v}=k_{w}=k_{\theta}=10^{9}, 10^{7}, 10^{6}, 10^{5}$, 


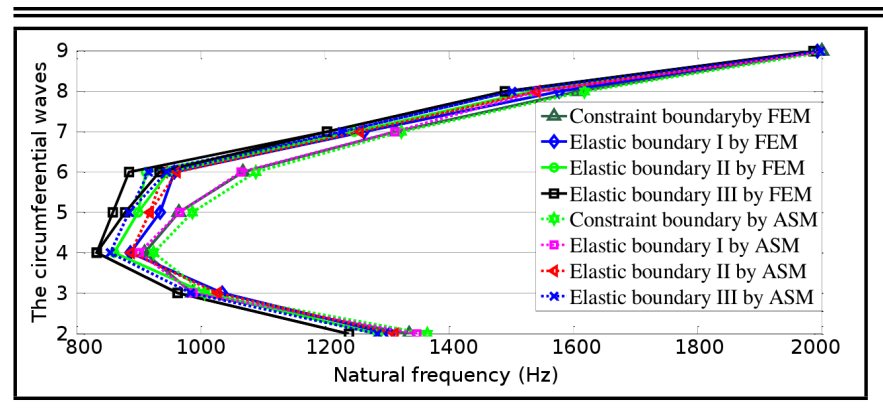

Figure 5. Calculated relation between natural frequency and modal shape under different elastic boundaries by ASM and.

and ASM method is used to calculate frequency results under the above two kinds of boundary conditions, as seen in Table 4. Further, the differences between FEM and ASM are also given in Table 4, and Fig. 5 gives the relation between natural frequency and modal shape calculated by the two theoretical methods. It should be noted that in the shape results calculated by FEM, $m$ represents the order of axial mode and $n$ represents the number of circumferential waves of TCS.

From Table 4, Table 5, and Fig. 5, it can be found that: (I) The elastic boundary has great influence on the inherent properties of the shell, which will lead to the decrease of the natural frequency, e.g., the reduced values of the first 8 natural frequencies are about $10 \sim 100 \mathrm{~Hz}$. (II) For some high order modes, their decreased degrees are very small. Taking the 7th and 8th natural frequencies for an example, the decreased degrees are less than $1 \%$. (III) Although frequencies and shapes of TCS will be changed by different kinds of elastic boundaries, the changing trend of natural frequencies with mode shapes is constant when the order of axial mode $m=1$, which shows frequency values is up after the decline with the increase of the number of circumferential waves $n$, and usually frequency values related to $n>8$ are higher than $n=2 \sim 7$.

\section{TEST SYSTEM AND METHOD OF MODAL PARAMETERS OF TCS UNDER ELASTIC BOUNDARY}

In Section 2, vibration characteristic of TCS under elastic boundary and its influence is analysed. But due to the complexity of elastic boundary, the real influence of such boundary on modal parameters, especially the damping characteristics of the shell cannot be accurately analysed by ASM or FEM. Therefore, it is necessary to employ experimental test to investigate the influence of elastic boundary on modal parameters of TCS. In this section, experiment system is first established to accurately measure modal parameters of the shell, and the corresponding test procedures and identification techniques suitable for the thin walled shell are also proposed.

\subsection{Test System of Modal Parameters of TCS Under Elastic Boundary}

On the one hand, due to light weight, closed modes, low level and complicated local vibration of TCS, traditional accelerometer will bring added mass and stiffness to the tested shell, which will severely affect the tested frequency and damping results, ${ }^{23}$ so laser Doppler vibrometer is used as noncontact response sensor to measure the vibration and frequency information of the shell. On the other hand, different excitation techniques also will result in test error, so the disadvantages of four common vibration excitation devices are compared in Table 6, and vibration shaker is finally chosen as excitation source with excitation level being precisely controlled, and test system of modal parameters of TCS under elastic boundary is given in Fig. 6. The instruments used in the test are as follows: (I) Polytec PDV-100 laser Doppler vibrometer; (II) kingdesign EM-1000F vibration shaker systems; (III) LongWei PS305DM DC power supply; (IV) Aslong JGA25 DC geared motor; (V) $45^{\circ}$ rotation mirror and $45^{\circ}$ fixed mirror; (VI) LMS SCADAS Mobile Front-End and Dell notebook computer.

In these devices, LMS SCADAS Mobile Front-End and Dell notebook computer are responsible for recording and saving response signal from laser Doppler vibrometer. Dell notebook computer with Intel Core i7 $2.93 \mathrm{GHz}$ processor and 4G RAM is used to operate LMS Test.Lab 12B software and store measured data. For the frequency and damping test, sine sweep excitation is conducted with a closed loop control via accelerometer on the countertop of the vibration shaker, and point1, point 2 , and point 3 (being $120^{\circ}$ with each other) are used to get response signal by adjusting laser point and average is used as the final results. In this test, natural frequency can be precisely determined through each resonant peak in frequency domain, and damping ratio can also be identified by the half-power bandwidth method which is calculated by measuring the bandwidth of the frequency curve (or approximately $3 \mathrm{~dB}$ ) down from the resonant peak. For modal shape test, laser rotating scanning technique is used to get shape results of TCS. First, one of natural frequencies of TCS is employed to drive the tested shell under the resonance state by vibration shaker, and then DC power supply is used to provide stable voltage and current for DC geared motor. The motor is used to drive the $45^{\circ}$ rotation mirror to complete a set of cross sectional scans with $360^{\circ}$ circumferential coverage for the tested shell, and in this way modal shape data at certain modes can be obtained in a shorter amount of time than traditional test methods.

\subsection{Test Method of Modal Parameters of TCS Under Elastic Boundary}

In this section, the test and identification techniques suitable for elastically supported shell are described in detail, as seen in the following three key steps.

\subsubsection{Accurately determine tightening torque under constraint boundary}

Because modal parameters of TCS are closely related to constraint boundary, in actual test, we must ensure that one end of the tested shell be effectively clamped. To this end, a torque wrench is used to determine the level of tightening torque on the M8 bolts of clamping-ring, as seen in Fig. 1, and the "pre-experiment" is adopted to determine the required tightening torque as well as to verify whether or not the tested shell is under constraint boundary. For instance, it should be done at least three times to test natural frequencies, and every time the same level of torque value should be applied on M8 bolts. If test results of the first three natural frequencies under three pre-experiments are close to each other (for example $1 \sim 3 \mathrm{~Hz}$ ), we will regard this torque value as the determined tightening torque under constraint boundary. If the differences between each natural frequency are big, more than $5 \sim 20 \mathrm{~Hz}$, 
H. Li, et al.: THE INFLUENCE OF ELASTIC BOUNDARY ON MODAL PARAMETERS OF THIN CYLINDRICAL SHELL

Table 4. Calculated natural frequencies of TCS under different elastic boundaries by ASM and FEM.

\begin{tabular}{|c|c|c|c|c|c|c|c|c|c|c|c|c|}
\hline & \multicolumn{3}{|c|}{ Constraint boundary } & \multicolumn{3}{c|}{ Elastic boundary I } & \multicolumn{3}{c|}{ Elastic boundary II } & \multicolumn{3}{c|}{ Elastic boundary III } \\
\hline $\begin{array}{c}\text { Modal } \\
\text { order }\end{array}$ & $\begin{array}{c}\text { AEM } \\
\text { A }\end{array}$ & $\begin{array}{c}\text { FEM } \\
\text { B }\end{array}$ & $\begin{array}{c}\text { Difference } \\
\left(\begin{array}{c}\text { A-B }) / B \\
(\%)\end{array}\right.\end{array}$ & $\begin{array}{c}\text { AEM } \\
\text { A }\end{array}$ & $\begin{array}{c}\text { FEM } \\
\text { B }\end{array}$ & $\begin{array}{c}\text { Difference } \\
(\mathrm{A}-\mathrm{B}) / \mathrm{B}\end{array}$ & $\begin{array}{c}\text { AEM } \\
\mathrm{A}\end{array}$ & $\begin{array}{c}\text { FEM } \\
\mathrm{B}\end{array}$ & $\begin{array}{c}\text { Diff. } \\
(\mathrm{A}-\mathrm{B}) / \mathrm{B} \\
(\%)\end{array}$ & $\begin{array}{c}\text { AEM } \\
\text { A }\end{array}$ & $\begin{array}{c}\text { FEM } \\
\text { B }\end{array}$ & $\begin{array}{c}\text { Difference } \\
(\mathrm{A}-\mathrm{B}) / \mathrm{B} \\
(\%)\end{array}$ \\
\hline 1 & 924.5 & 910.4 & 1.5 & 901.4 & 886.5 & 1.7 & 887.6 & 860.5 & 3.1 & 854.3 & 832.6 & 2.6 \\
\hline 2 & 987.4 & 965.4 & 2.3 & 966.5 & 934.5 & 3.4 & 917.8 & 899.4 & 2.0 & 884.5 & 878.5 & 0.7 \\
\hline 3 & 1006.4 & 986.5 & 2.0 & 988.3 & 957.3 & 3.2 & 961.5 & 948.1 & 1.4 & 945.7 & 933.6 & 1.3 \\
\hline 4 & 1089.2 & 1068.7 & 1.9 & 1065.2 & 1035.4 & 2.9 & 1027.7 & 1006.9 & 2.1 & 983.6 & 972.7 & 1.1 \\
\hline 5 & 1323.6 & 1313.8 & 0.7 & 1312.5 & 1263.1 & 3.9 & 1256.7 & 1247.3 & 0.8 & 1227.6 & 1203.7 & 2.0 \\
\hline 6 & 1365.4 & 1335.9 & 2.2 & 1348.8 & 1305.2 & 3.3 & 1313.4 & 1286 & 2.1 & 1284.4 & 1239 & 3.7 \\
\hline 7 & 1618.1 & 1608.2 & 0.6 & 1584.6 & 1577.2 & 0.5 & 1541.6 & 1532.8 & 0.6 & 1521.9 & 1509.9 & 0.8 \\
\hline 8 & 2017.5 & 2000.8 & 0.8 & 2009.6 & 1992.8 & 0.8 & 2001.5 & 1988 & 0.7 & 1998.3 & 1986.9 & 0.6 \\
\hline
\end{tabular}

Table 5. Calculated modal shapes of TCS under different elastic boundaries by FEM.

\begin{tabular}{|c|c|c|c|c|}
\hline $\begin{array}{c}\text { Modal } \\
\text { order }\end{array}$ & $\begin{array}{c}\text { Constraint boundary } \\
(m, n)\end{array}$ & $\begin{array}{c}\text { Elastic boundary I } \\
(m, n)\end{array}$ & $\begin{array}{c}\text { Elastic boundary II } \\
(m, n)\end{array}$ & $\begin{array}{c}\text { Elastic boundary III } \\
(m, n)\end{array}$ \\
\hline 1 & $(1,4)$ & $(1,4)$ & $(1,4)$ & $(1,4)$ \\
\hline 2 & $(1,5)$ & $(1,5)$ & $(1,5)$ & $(1,5)$ \\
\hline 3 & $(1,3)$ & $(1,3)$ & $(1,6)$ & $(1,6)$ \\
\hline 4 & $(1,6)$ & $(1,6)$ & $(1,3)$ & $(1,3)$ \\
\hline 5 & $(1,7)$ & $(1,7)$ & $(1,7)$ & $(1,7)$ \\
\hline 6 & $(1,2)$ & $(1,2)$ & $(1,2)$ & $(1,2)$ \\
\hline 7 & $(1,8)$ & $(1,8)$ & $(1,8)$ & $(1,8)$ \\
\hline 8 & $(1,9)$ & $(1,9)$ & $(1,9)$ & $(1,9)$ \\
\hline
\end{tabular}

we need to increase torque value and repeat pre-experiments several times.

\subsubsection{Measure modal parameters of TCS under con- straint boundary}

This step involves three different measurements and identification techniques. First, using sine sweep excitation by vibration shaker to test natural frequencies of TCS, and in order to get precise frequency results, the small-segment FFT processing technique is employed to deal with the measured sweep signal. The time domain signal involving the 3rd natural frequency of the tested shell is shown in Fig. 7(a). If FFT processing technique is directly applied on this sweep signal, we can obtain its frequency spectrum, as seen in Fig. 7(b), and the frequency of the response peak is $1024.8 \mathrm{~Hz}$. However, if the whole time of sweep signal can be divided into small segments, and we conduct FFT on each segment of them (in this example, it is $1 \mathrm{~s}$ with respect to the whole time of $68 \mathrm{~s}$ ), the resulting frequency spectrum, as seen in Fig. 7(c), is plotted through the combination of the response peak of each segment (also treated with interpolation and smoothing). The frequency value related to the peak is $1025.7 \mathrm{~Hz}$, which is truly accurate result of the 3th natural frequency. Therefore, for time-dependent sweep signal of TCS, it is necessary to use the small-segment FFT processing technique to accurately get frequency results.

Then, use the half-power bandwidth technique to identify each damping ratio of TCS from the frequency spectrum obtained by small-segment FFT processing technique. Because the resonant peak in the spectrum is already known, we can identify two half-power bandwidth points by measuring the bandwidth of the frequency curve (or approximately $3 \mathrm{~dB}$ ) down from the resonant peak, consequently according to the damping formula to calculate the corresponding damping results based the MATLAB program. Figure 8 gives time waveform and frequency spectrum for the 3 rd natural frequency and damping ratio of TCS at three measuring points. In order to 


Table 6. Disadvantages of different vibration excitation devices for modal test of TCS under elastic boundary.
\begin{tabular}{|c|c|c|c|c|}
\hline $\begin{array}{c}\text { Excitation } \\
\text { device }\end{array}$ & \multicolumn{2}{|c|}{ Modal parameters of TCS } & Disadvantage \\
\cline { 2 - 5 } & $\begin{array}{c}\text { Natural } \\
\text { frequency }\end{array}$ & $\begin{array}{c}\text { Mode } \\
\text { shape }\end{array}$ & $\begin{array}{c}\text { Damping } \\
\text { ratio }\end{array}$ & Pulse excitation level can not be precisely controlled and the excitation \\
Hammer & $\sqrt{ }$ & $\sqrt{ }$ & $\times$ & $\begin{array}{l}\text { Porce varies for each measurement, and double hit can often lead to test } \\
\text { errors. }\end{array}$ \\
\hline Electromagneti c exciter & $\times$ & $\times$ & $\times$ & $\begin{array}{l}\text { The related force sensor will bring added mass and stiffness to TCS, } \\
\text { which will severely affect test results of damping and natural frequency. }\end{array}$ \\
\hline Piezoelectric Ceramic exciter & $\sqrt{ }$ & $\sqrt{ }$ & $\times \begin{array}{l}\text { The excitation energy of piezoelectric ceramic exciter is often insuffi- } \\
\text { cient for TCS, which will result in poor response signal with low level } \\
\text { of signal noise ratio. }\end{array}$ \\
\hline Vibration shaker & $\sqrt{ }$ & $\sqrt{ }$ & $\sqrt{ }$ & $\begin{array}{l}\text { Excitation frequencies are not that high, which are often limited to } \\
1 \text { Hz } \sim 3000 \text { Hz, and the test procedures are often complicated. }\end{array}$ \\
\hline
\end{tabular}

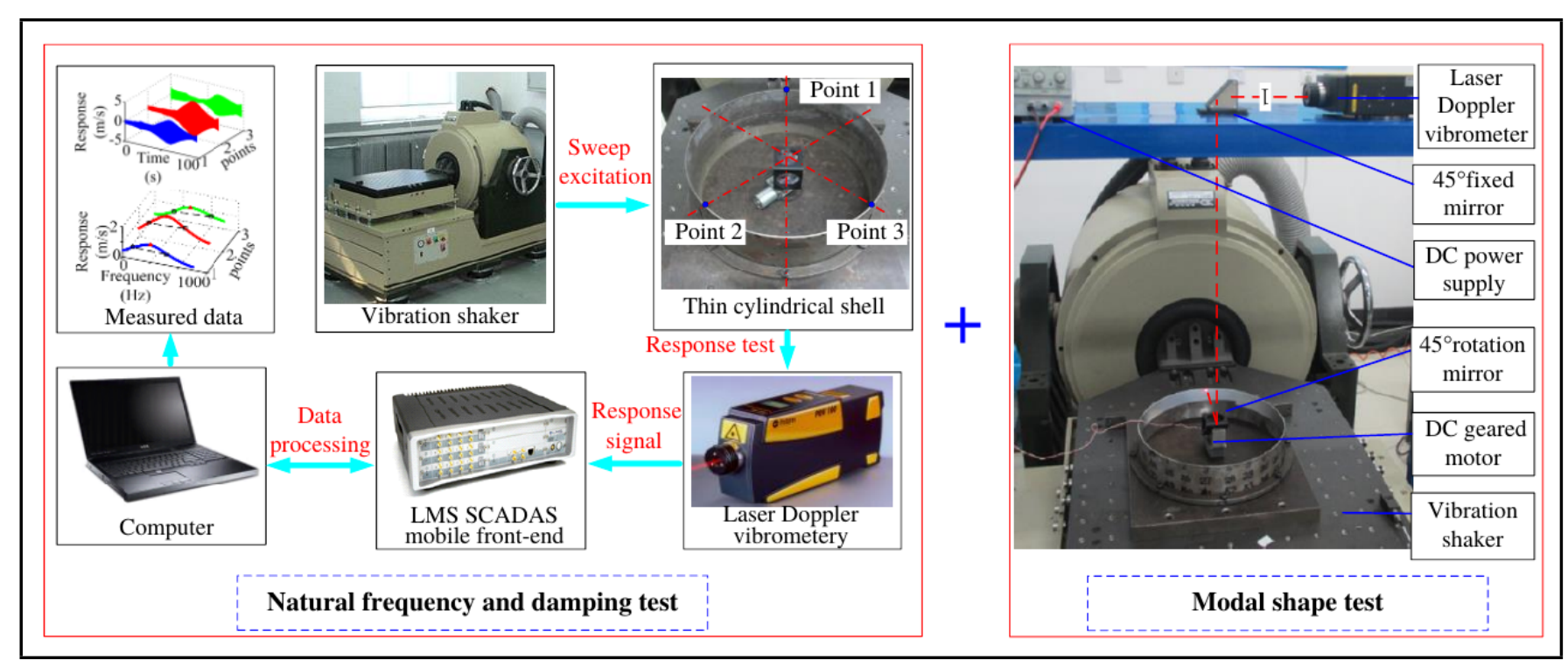

Figure 6. Schematic of test system of modal parameters of TCS under elastic boundary.

improve accuracy of frequency and damping results, the final results is obtained by averaging the test results at these points.

Finally, using each natural frequency to excite TCS at resonance state, each modal shape with obvious reduction in time costs by laser rotating scan method is obtained.

\subsubsection{Measure modal parameters of TCS under elas- tic boundary}

After finishing the measurement work under constraint boundary, we can fill $1 \mathrm{~mm}, 2 \mathrm{~mm}$, and $3 \mathrm{~mm}$ rubber ring made by $\mathrm{ZN} 33$ elastomer into the position between the clampingring and extension edge to simulate different elastic boundary conditions, which named as elastic boundary I, elastic boundary II, and elastic boundary III respectively. Then, experimental test is conducted to get natural frequencies, modal shapes, and damping ratios with the same test methods, such as the small-segment FFT processing technique, the half-power bandwidth technique, and laser rotating scan technique used in the above two steps. It should be noted that the excitation level and the position of the three measuring points must be the same as the ones under constraint boundary.

\section{INFLUENCE ANALYSIS OF MODAL PA- RAMETERS OF TCS UNDER ELASTIC BOUNDARY}

In this section, on the basis of both theoretical and experimental results, i.e., the simulation results calculated by ASM and FEM in Section 2 and the accurate measured data obtained by the test system and test method described in the Section 3, the influence on natural frequencies, modal shapes, and damping ratios of TCS under elastic boundary are analysed and discussed in detail.

\subsection{Test Results of Modal Parameters of TCS Under Elastic Boundary}

According to the proposed test method and procedures in Section 3, point 1 , point 2 , and point 3 are used as the response points, which are $120^{\circ}$ with each other, and in the same cross section of the shell, the axial distance from this section to free end of TCS is about 5mm, as seen in Fig. 6. For the natural frequency and damping test, the following set-ups and parameters are chosen: (I) excitation level of $1 \mathrm{~g}$; (II) sweep rate of $1 \mathrm{~Hz} / \mathrm{s}$; (III) frequency resolution of $0.125 \mathrm{~Hz}$; (IV) hanning window for sweep response signal with upward sweep direction; (V) frequency range of 0-2048 Hz. For the modal shape test, the following set-ups and parameters are chosen: (I) excitation level of $1 \mathrm{~g} \sim 3 \mathrm{~g}$; (II) frequency resolution of $0.125 \mathrm{~Hz}$; (III) rectangular window for stable response signal; (IV) sampling frequency of $12800 \mathrm{~Hz}$; (V) rotated scan speed of $2 \mathrm{r} / \mathrm{min}$. Besides, the first eight modal shapes of TCS are obtained in the test, and each modal shape is assembled from two sets of cross sectional scans, one is in the section which includes point 1 , point 2 , and point 3 , the other is about $25 \mathrm{~mm}$ to the clamped end of the shell (restricted by the height of DC geared motor itself, but do not affect the test results when the 


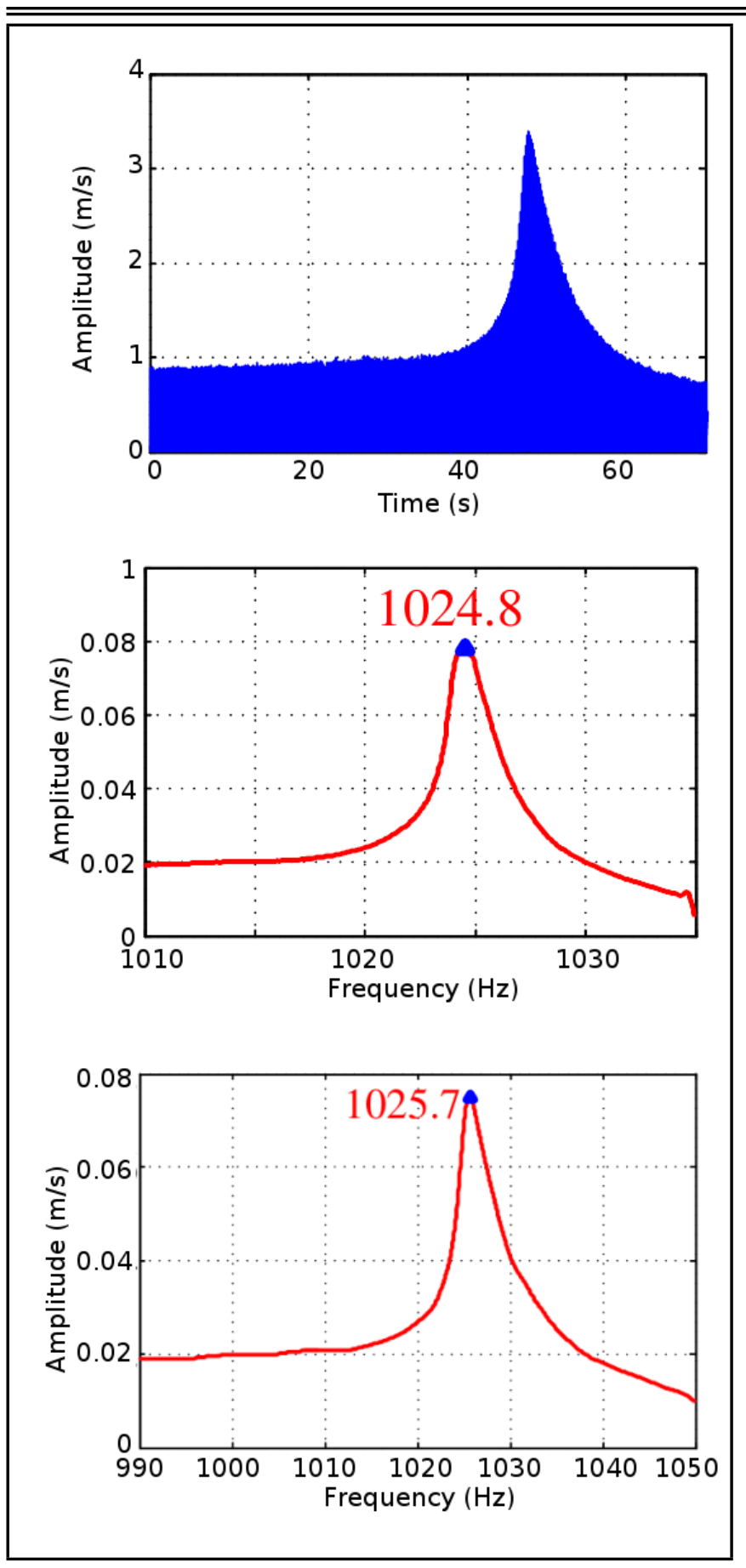

Figure 7. 3rd natural frequency of TCS obtained by different FFT processing techniques.

order of axial mode $m=1$ ).

The measured frequency, damping, and shape results under constraint boundary as well as different elastic boundaries are listed in Table 7, Table 8, and Table 9, respectively. Besides, in order to clearly describe the effect degree and trend of the elastically supported shell, the corresponding scattergrams of natural frequencies and damping ratios of TCS under such boundary are also given, as shown in Fig. 9 and Fig. 10, and Fig. 11 gives the relation between natural frequency and modal shape under elastic boundary.
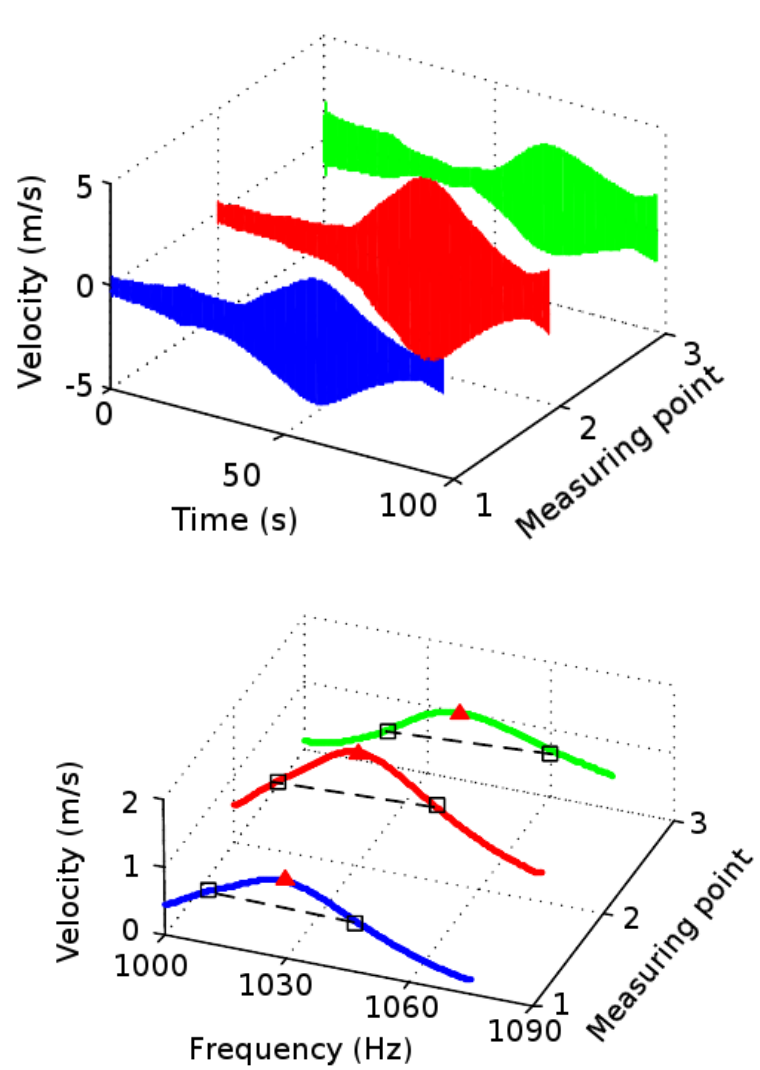

Figure 8. Time waveform and frequency spectrum for the 3 rd natural frequency and damping ratio of TCS under constraint boundary at 3 measuring points.

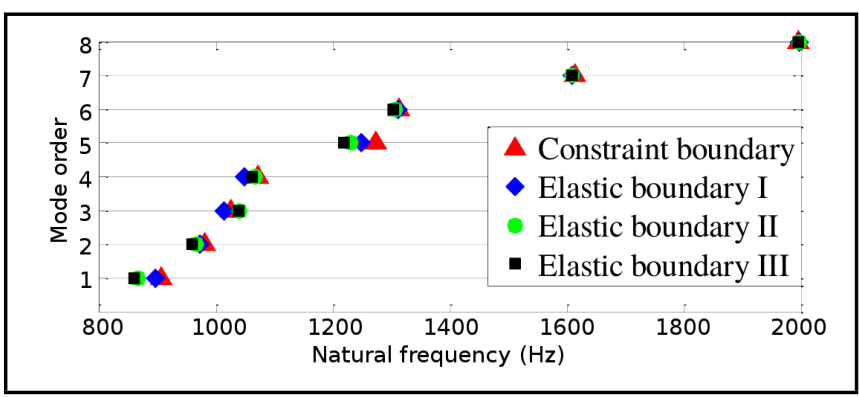

Figure 9. Scattergram of natural frequencies of TCS under different elastic boundaries.

\subsection{Influence Analysis of Modal Parameters Under Elastic Boundary}

\subsubsection{Influence on natural frequencies of TCS}

From Table 7 and Fig. 9, it can be found that: (I) When the boundary condition of TCS is changed into elastic boundary, the natural frequencies of most modes will decrease within the range of $1 \sim 54 \mathrm{~Hz}$, which are similar to the calculated results and they verify the correctness of theoretical analysis conclusion. (II) For the low order natural frequencies of the shell, they would decrease by much more, e.g., the decreased degree of the 1 st frequency result can reach to $5 \%$. (III) For the high order natural frequencies of the shell, they are basically not affected by elastic boundary. Taking the 7 th and 8th natural frequencies for an example, they only change $0.3 \%$ compared with the ones under the fixed state. (IV) For some modes, 
Table 7. Measured natural frequencies of TCS under different elastic boundaries.

\begin{tabular}{|c|c|c|c|c|c|c|c||}
\hline $\begin{array}{c}\text { Mode } \\
\text { order }\end{array}$ & $\begin{array}{c}\text { Constraint } \\
\text { boundary } \\
\mathrm{A}(\mathrm{Hz})\end{array}$ & $\begin{array}{c}\text { Elastic } \\
\text { boundary I } \\
\mathrm{B}(\mathrm{Hz})\end{array}$ & $\begin{array}{c}\text { Difference } \\
(\mathrm{B}-\mathrm{A}) / \mathrm{A} \\
(\%)\end{array}$ & $\begin{array}{c}\text { Elastic } \\
\text { boundary II } \\
\mathrm{C}(\mathrm{Hz})\end{array}$ & $\begin{array}{c}\text { Difference } \\
(\mathrm{C}-\mathrm{A}) / \mathrm{A} \\
(\%)\end{array}$ & $\begin{array}{c}\text { Elastic } \\
\text { boundary III } \\
\mathrm{D}(\mathrm{Hz})\end{array}$ & $\begin{array}{c}\text { Difference } \\
(\mathrm{D}-\mathrm{A}) / \mathrm{A} \\
(\%)\end{array}$ \\
\hline 1 & 906.3 & 896.7 & -1.1 & 866.4 & -4.4 & 860.6 & -5 \\
\hline 2 & 980.8 & 972.4 & -0.9 & 966.1 & -1.5 & 959.5 & -2.2 \\
\hline 3 & 1025.7 & 1014.6 & -1.1 & 1040.2 & 1.4 & 1039 & 1.3 \\
\hline 4 & 1072.3 & 1048.7 & -2.2 & 1067.6 & -0.4 & 1062.6 & -0.9 \\
\hline 5 & 1274.0 & 1248.5 & -2.0 & 1231.3 & -3.4 & 1219.8 & -4.3 \\
\hline 6 & 1312.8 & 1312.0 & -0.1 & 1307.2 & -0.4 & 1303.4 & -0.7 \\
\hline 7 & 1613.8 & 1609.3 & -0.3 & 1608.3 & -0.3 & 1608.5 & -0.3 \\
\hline 8 & 1996.3 & 1997.0 & 0 & 1997.3 & 0.1 & 1995.3 & -0.1 \\
\hline
\end{tabular}

Table 8. Measured damping ratios of TCS under different elastic boundaries

\begin{tabular}{|c|c|c|c|c|c|c|c||}
\hline $\begin{array}{c}\text { Mode } \\
\text { order }\end{array}$ & $\begin{array}{c}\text { Constraint } \\
\text { boundary } \\
\mathrm{A}(\mathrm{Hz})\end{array}$ & $\begin{array}{c}\text { Elastic } \\
\text { boundary I } \\
\mathrm{B}(\mathrm{Hz})\end{array}$ & $\begin{array}{c}\text { Difference } \\
(\mathrm{B}-\mathrm{A}) / \mathrm{A} \\
(\%)\end{array}$ & $\begin{array}{c}\text { Elastic } \\
\text { boundary II } \\
\mathrm{C}(\mathrm{Hz})\end{array}$ & $\begin{array}{c}\text { Difference } \\
(\mathrm{C}-\mathrm{A}) / \mathrm{A} \\
(\%)\end{array}$ & $\begin{array}{c}\text { Elastic } \\
\text { boundary III } \\
\mathrm{D}(\mathrm{Hz})\end{array}$ & $\begin{array}{c}\text { Difference } \\
(\mathrm{D}-\mathrm{A}) / \mathrm{A} \\
(\%)\end{array}$ \\
\hline 1 & 0.20 & 0.54 & 170.0 & 0.70 & 250.0 & 1.16 & 480.0 \\
\hline 2 & 0.76 & 0.46 & -39.5 & 0.63 & -17.1 & 0.63 & -17.1 \\
\hline 3 & 1.14 & 0.55 & -51.8 & 0.50 & -56.1 & 1.01 & -12.3 \\
\hline 4 & 0.27 & 0.4 & 48.1 & 0.44 & 63.0 & 0.62 & 129.6 \\
\hline 5 & 0.74 & 0.83 & 12.2 & 0.80 & 8.1 & 0.82 & 10.8 \\
\hline 6 & 0.37 & 0.4 & 8.1 & 0.39 & 5.4 & 0.68 & 83.8 \\
\hline 7 & 0.39 & 0.18 & -53.8 & 0.19 & -51.3 & 0.20 & -48.7 \\
\hline 8 & 0.30 & 0.11 & -63.3 & 0.27 & -10.0 & 0.28 & -6.7 \\
\hline
\end{tabular}

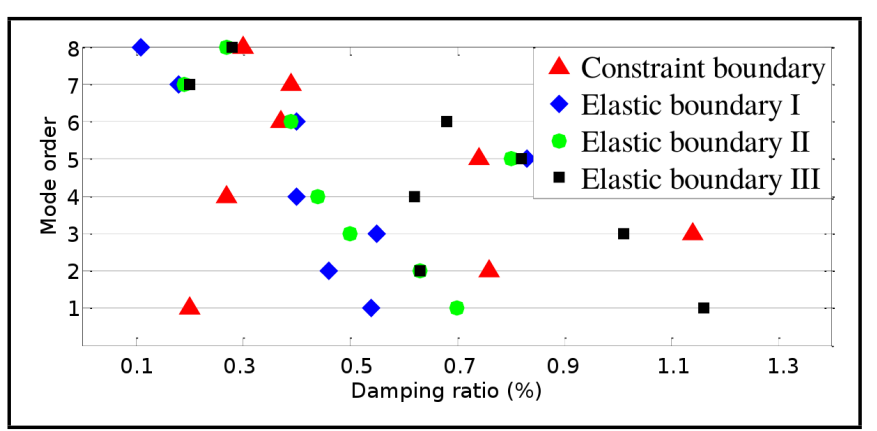

Figure 10. Scattergram of damping ratios of TCS under different elastic boundaries.

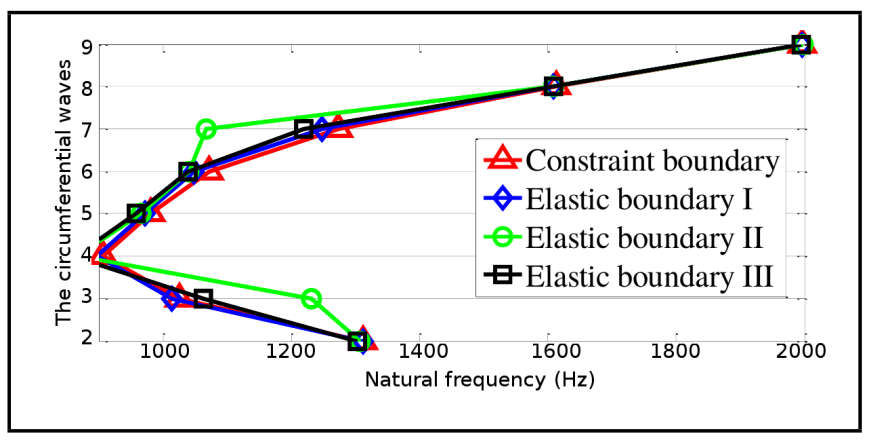

Figure 11. Measured relation between natural frequency and modal shape of TCS under different elastic boundaries.

with the increase of the thickness of rubber ring, their natural frequencies will go up instead of decreasing. For example, the maximum increased degree of the 3rd natural frequency of TCS can reach to $1.4 \%$, which might be caused by the changes of modal shapes under elastic boundary.

Comparing the 3rd and 4th frequency results in Table 4 obtained by ASM and FEM with the experiment results in Table 7 , we can find that the calculated frequency results have declined monotonically, which are not the same as that of the experiment results when the constraint boundary is turned into the elastic boundary. The possible reasons for this error is that: (I) because of the complicated connection condition un- der elastic boundary, it is hard for ASM and FEM to simulate such elastic boundary well, so the theoretical results may inevitably contain some errors. (II) the occurrence sequence of modal shape has changed such as the $3 \mathrm{rd}$ and 4 th modal shape (for example, the 3rd modal shape is changed from $(1,3)$ to $(1,6)$ when the constraint boundary (or elastic boundary I) is turned into the elastic boundary II (or elastic boundary III)). Although the calculated shape results can simulate the variation of experimental results, it is hard for the calculated frequency results to be very close to all of the experiment results. However, the decreased trend of natural frequency is true if we observe the whole 1-8 natural frequency results (except for the third mode) obtained by experiment in Tables 7 .

\subsubsection{Influence on damping ratios of TCS}

From Table 8 and Fig. 10, it can be found that: (I) The elastic boundary has great influence on the damping characteristics of TCS; it will not only increase the damping of some modes, but also may lead to the decrease of the damping for part of modes of the shell. Therefore, in the process of vibration-reduction design, it is necessary to choose proper frequency range, otherwise elastic boundary may produce negative effects. (II) When the boundary condition of TCS is changed into elastic boundary, it would clearly reduce high order damping. Taking the 7 th and 8th damping results for an example, the range of the decreased degree can reach to about $53 \% \sim 63 \%$. (III) The elastic boundary may improve damping of the low and intermediate mode of TCS, especially for the 1st damping results, the increased degree is more than $480 \%$ compared with the ones under constraint boundary.

\subsubsection{Influence on modal shapes of TCS}

From Table 9 and Fig. 11, it can be found that: (I) When the support stiffness of elastic boundary is larger, i.e., the thickness of rubber ring is only $1 \mathrm{~mm}$ (which means that the boundary condition is just turned into elastic-support from the fixed-support), the resulting shapes of TCS can hardly be changed. (II) As elastic boundary condition changes with increased thicknesses of rubber ring, low order modal shapes of 
Table 9. Measured modal shapes of TCS under different elastic boundaries

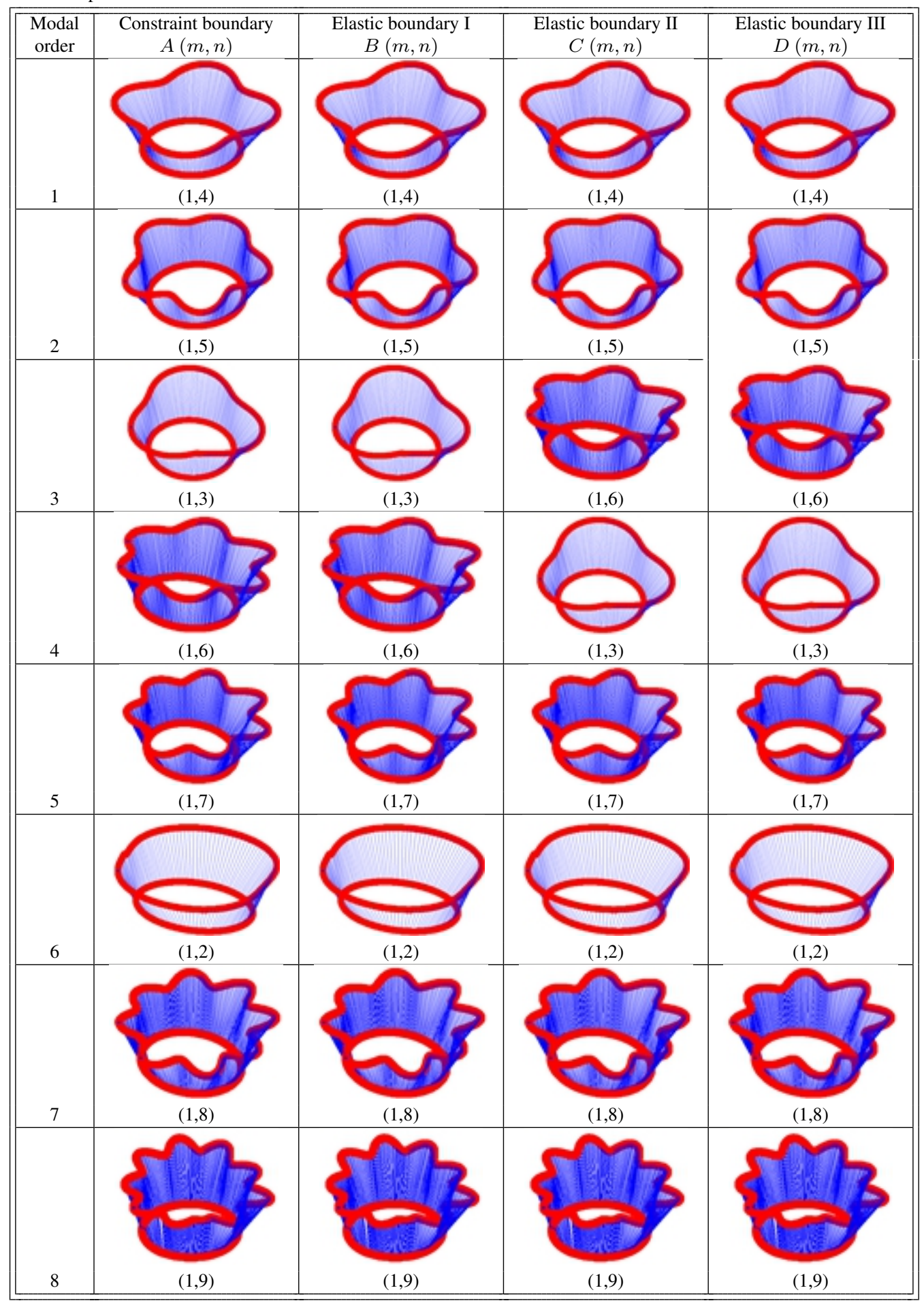

TCS vary that different levels, but for medium and high order modes, such as the 6th, 7th, and 8th shape results, they are unchanged and still the same as the ones under constraint boundary. (III) Although frequencies and shapes of TCS will be changed by different kinds of elastic boundaries, the changing trend of natural frequencies with mode shapes is constant when the order of axial mode is $m=1$, which shows frequency values are up after the decline with the increase of the number of circumferential waves $\mathrm{n}$, and usually frequency values related to $n>8$ are higher than $n=2 \sim 7$. This verified the correctness of theoretical analysis conclusion.

\section{CONCLUSIONS}

This research combines theory with experiment to investigate the influence of elastic boundary on modal parameters of TCS. Based on the analysis and experimental results, the following conclusions can be drawn:

(1) FEM and ASM are adopted to roughly master vibration characteristics of shell structure, and the theoretical analysis results are helpful for us to determine measured frequency range, build experimental model, understand geographic distributions of some nodes or nodal lines etc.

(2) Test system and method under elastic boundary is proposed to accurately measure modal parameters of TCS, and the following measurements and identification techniques are used 
to get precise frequency, damping and shape results: (I) Noncontact laser Doppler vibrometer and vibration shaker with excitation level being precisely controlled are used in the test system; (II) "Pre-experiment" is adopted to determine the required tightening torque under constraint boundary; (III) The smallsegment FFT processing technique is employed to accurately measure nature frequency; (IV) Laser rotating scanning technique is used to get shape results with high efficiency.

(3) The influence on natural frequencies, modal shapes, and damping ratios of TCS under elastic boundary are analysed and discussed. It can be found that elastic boundary can significantly affect modal parameters of TCS, which would reduce high order damping obviously. For example, the 7th and 8th damping can be decreased within the range of $53 \% \sim 63 \%$. Besides, natural frequencies of most modes will also be decreased within the range of $1 \sim 54 \mathrm{~Hz}$. However, high order natural frequencies and mode shapes are still the same as the ones under constraint condition, and the changing trend of natural frequencies with mode shapes is constant when the order of axial mode is $m=1$, which agrees well with the results calculated by ASM and FEM.

\section{ACKNOWLEDGEMENT}

This study was supported by the National Natural Science Foundation of China granted No. 51505070, the Fundamental Research Funds for the Central Universities of China granted No. N150304011 and N160313002, and the Key Laboratory of Vibration and Control of Aero-Propulsion System Ministry of Education, Northeastern University, granted No. VCAME201603.

\section{CONFLICT OF INTERESTS}

The authors declare that there is no conflict of interests regarding the publication of this paper.

\section{APPENDICES}

\section{Appendix A - The Elements in the Stiffness Matrix K}

$$
k_{i j}^{a a}=\int_{0}^{1} 2\left[\frac{R^{2}}{L^{2}} \varphi_{i}^{u^{\prime}}(\xi) \varphi_{i}^{u^{\prime}}(\xi)+\frac{n^{2}(1-\mu)}{2} \varphi_{i}^{u}(\xi) \varphi_{j}^{u}(\xi)\right] \mathrm{d} \xi
$$

$$
\begin{aligned}
& k_{i j}^{a b}= \\
& \int_{0}^{1}\left[-n(1-\mu) \frac{R}{L} \varphi_{i}^{u}(\xi) \varphi_{j}^{v^{\prime}}(\xi)+2 \mu n \frac{R}{L} \varphi_{i}^{u^{\prime}}(\xi) \varphi_{j}^{v}(\xi)\right] \mathrm{d} \xi
\end{aligned}
$$

$$
k_{i j}^{a c}=\int_{0}^{1}\left[2 \mu \frac{R}{L} \varphi_{i}^{u^{\prime}}(\xi) \varphi_{j}^{w}(\xi)\right] \mathrm{d} \xi
$$

$$
\begin{aligned}
& k_{i j}^{b a}= \\
& \int_{0}^{1}\left[-n(1-\mu) \frac{R}{L} \varphi_{i}^{v^{\prime}}(\xi) \varphi_{j}^{u}(\xi)+2 \mu n \frac{R}{L} \varphi_{i}^{v}(\xi) \varphi_{j}^{u^{\prime}}(\xi)\right] \mathrm{d} \xi
\end{aligned}
$$

$$
k_{i j}^{b b}=\int_{0}^{1} 2\left[\begin{array}{c}
\left(\frac{n^{2} H^{2}}{12 R^{2}}+n^{2}\right) \varphi_{i}^{v}(\xi) \varphi_{j}^{v}(\xi) \\
+(1-\mu)\left(\frac{R^{2}}{2 L^{2}}+\frac{H^{2}}{24 L^{2}}\right) \varphi_{i}^{v^{\prime}}(\xi) \varphi_{j}^{v^{\prime}}(\xi)
\end{array}\right] \mathrm{d} \xi
$$

$$
\begin{gathered}
k_{i j}^{b c}=\int_{0}^{1} 2\left[\begin{array}{c}
\left(\frac{n^{3} H^{2}}{6 R^{2}}+2 n\right) \varphi_{i}^{v}(\xi) \varphi_{j}^{w}(\xi) \\
+(1-\mu) \frac{n H^{2}}{6 L^{2}} \\
\varphi_{i}^{v^{\prime}}(\xi) \varphi_{j}^{w^{\prime}}(\xi) \\
-\frac{\mu n H^{2}}{6 L^{2}} \varphi_{i}^{v}(\xi) \varphi_{j}^{w^{\prime \prime}}(\xi)
\end{array}\right] \mathrm{d} \xi ; \\
k_{i j}^{c a}=\int_{0}^{1}\left[2 \mu \frac{R}{L} \varphi_{i}^{w}(\xi) \varphi_{j}^{u^{\prime}}(\xi)\right] \mathrm{d} \xi
\end{gathered}
$$

$$
k_{i j}^{c b}=\int_{0}^{1} 2\left[\begin{array}{c}
\left(\frac{n^{3} H^{2}}{6 R^{2}}+2 n\right) \varphi_{i}^{w}(\xi) \varphi_{j}^{v}(\xi) \\
+(1-\mu) \frac{n H^{2}}{6 L^{2}} \varphi_{i}^{w^{\prime}}(\xi) \varphi_{j}^{v^{\prime}}(\xi) \\
-\frac{\mu n H^{2}}{6 L^{2}} \varphi_{i}^{w^{\prime \prime}}(\xi) \varphi_{j}^{v}(\xi)
\end{array}\right] \mathrm{d} \xi
$$

$$
k_{i j}^{c c}=\int_{0}^{1} 2\left[\begin{array}{c}
2\left(\frac{H^{2} n^{4}}{12 R^{2}}+1\right) \varphi_{i}^{w}(\xi) \varphi_{j}^{w}(\xi) \\
+(1-\mu) \frac{n^{2} H^{2}}{6 L^{2}} \varphi_{i}^{w^{\prime}}(\xi) \varphi_{i}^{w^{\prime}}(\xi) \\
+\frac{H^{2} R^{2}}{12 L^{2}} \varphi_{i}^{w^{\prime \prime}}(\xi) \varphi_{i}^{w^{\prime \prime}}(\xi) \\
-\frac{\mu n^{2} H^{2}}{6 L^{2}} \varphi_{i}^{w^{\prime \prime}}(\xi) \varphi_{j}^{w}(\xi)
\end{array}\right] \mathrm{d} \xi ;
$$

\section{Appendix B - The Elements in Artificial Spring Stiffness Matrix $\mathbf{K}_{S P}$}

$$
\begin{gathered}
k s_{i j}^{a a}=\tilde{k}_{0}^{u} \varphi_{i}^{u}(0) \varphi_{j}^{u}(0)+\tilde{k}_{1}^{u} \varphi_{i}^{u}(1) \varphi_{j}^{u}(1) \\
k s_{i j}^{b b}=\tilde{k}_{0}^{v} \varphi_{i}^{v}(0) \varphi_{j}^{v}(0)+\tilde{k}_{1}^{v} \varphi_{i}^{v}(1) \varphi_{j}^{v}(1) \\
k s_{i j}^{c c}=\tilde{k}_{0}^{w} \varphi_{i}^{w}(0) \varphi_{j}^{w}(0)+\tilde{k}_{1}^{w} \varphi_{i}^{w}(1) \varphi_{j}^{w}(1) \\
+\tilde{k}_{0}^{\theta}\left[\varphi_{i}^{w}(0)\right]^{\prime}\left[\varphi_{j}^{w}(0)\right]^{\prime}+\tilde{k}_{1}^{\theta}\left[\varphi_{1}^{w}(1)\right]^{\prime}\left[\varphi_{1}^{w}(1)\right]^{\prime}
\end{gathered}
$$


Appendix C - The Elements in Mass Matrix M

$$
\begin{aligned}
& M_{i j}^{a a}=\int_{0}^{1} \varphi_{i}^{u} \varphi_{j}^{u} \mathrm{~d} \xi \\
& M_{i j}^{b b}=\int_{0}^{1} \varphi_{i}^{v} \varphi_{j}^{v} \mathrm{~d} \xi ; \\
& M_{i j}^{c c}=\int_{0}^{1} \varphi_{i}^{w} \varphi_{j}^{w} \mathrm{~d} \xi
\end{aligned}
$$

\section{REFERENCES}

1 Leissa, A. W., Vibrations of shells, Acoustical Society of America, Ohio (1973).

2 Soedel, W., Vibrations of Shells and Plates, Marcel Dekker, New York (2004).

3 Goldman, R. L., Mode shapes and frequencies of clampedclamped cylindrical shells, AIAA Journal, 12 (12) (1974) 1755-1756. https://dx.doi.org/10.2514/3.49599

4 Ewins, D. J., Modal Testing: Theory and Practice, Research Studies Press Ltd, Baldock (1984).

5 Zang, C. and Ewins, D. J., Model validation for structural dynamics in the aero-engine design process, Frontiers of Energy \& Power Engineering in China, 3 (2009) 480-488. https://dx.doi.org/10.1007/s11708-009-0043-8

6 Shan, Y. C., Hao, Y. P., Zhu, Z. G., and Yan, L. T., Application and development of platform friction damper for depressing resonant vibration of blades, Journal of Aerospace Power, 16 (3) (2001) 218-223. https://dx.doi.org/10.3969/j.issn.1000-8055.2001.03.005

7 Fan, T. Y., Vibration reduction by elastic support dry friction damper, Ph.D, Northwestern Polytechnical University, Xi'an, China (2006).

8 Malekzadeh, P., Haghighi, M. R. G., and Atashi, M. M., Free vibration analysis of elastically supported functionally graded annular plates subjected to thermal environment, Meccanica, 46 (5) (2011) 893-913. https://dx.doi.org/10.1007/s11012-010-9345-5

9 Jin, G., Su, Z., Ye, T., and Jia, X., Three-dimensional vibration analysis of isotropic and orthotropic conical shells with elastic boundary restraints, International Journal of Mechanical Sciences, 89 (2014) 207-221. https://dx.doi.org/10.1016/j.ijmecsci.2014.09.005

10 Wang, H. T., Casing stiffness analysis of pretightening force bolt joint, Aeroengine, 36 (3) (2010) 32-35. https://dx.doi.org/10.3969/j.issn.1672-3147.2010.03.009

11 Forsberg, K., Influence of boundary conditions on the modal characteristics of thin cylindrical shells, AIAA Journal, 2 (12) (1964) 2150-2157. https://dx.doi.org/10.2514/3.55115
12 Koga, T., Effects of boundary conditions on the free vibrations of circular cylindrical shells, AIAA Journal, 26 (11) (1988) 1387-1394. https://dx.doi.org/10.2514/3.10052

13 Amabili, M. and Dalpiaz, G., Free vibrations of cylindrical shells with non-axisymmetric mass distribution on elastic bed, Meccanica, 32 (32) (1997) 71-84. https://dx.doi.org/10.1006/jfls.2000.0288

14 Loveday, P. W. and Rogers, C. A., Free vibration of elastically supported thin cylinders including gyroscopic effects, Journal of Sound and Vibration, 217 (3) (1998) 547-562. https://dx.doi.org/10.1006/jsvi.1998.1765

15 Liang, B. and Zhang, W., Two types of optimization of cylindrical shell on deformation, Journal of Ship Mechanics, 9 (4) (2005) 98-102. https://dx.doi.org/10.1016/j.ijpvp.2006.04.001

16 Zhou, H., Li, W., Lv, B., and Li, W. L., Free vibrations of cylindrical shells with elastic-support boundary conditions, Applied Acoustics, 73 (8) (2012) 751-756. https://dx.doi.org/10.1016/.apacoust.2012.02.008

17 Sun, S. P., Study on dynamic characteristics of rotating thin-walled cylindrical shells, Ph.D, Harbin Institute of Technology, Harbin, China (2013).

$18 \mathrm{Wu}$, S., Qu, Y., and Hua, Y., Vibrations characteristics of joined cylindrical-spherical shell with elasticsupport boundary conditions, Journal of Mechanical Science \& Technology, 27 (5) (2013) 1265-1272. https://dx.doi.org/10.1007/s12206-013-0207-7

19 Chen, Y., Jin, G., and Liu, Z., Free vibration analysis of circular cylindrical shell with nonuniform elastic boundary constraints, International Journal of Mechanical Sciences, 74 (3) (2013) 120-132. https://dx.doi.org/10.1016/j.ijmecsci.2013.05.006

20 Yuan, J., Dickinson, S. M. The free vibration of circularly cylindrical shell and plate systems. Journal of Sound and Vibration, 175 (2) (1994) 241-263. https://dx.doi.org/10.1006/jsvi.1994.1326

21 Sun, S., Cao, D., and Han, Q. Vibration studies of rotating cylindrical shells with arbitrary edges using characteristic orthogonal polynomials in the Rayleigh-Ritz method. International Journal of Mechanical Sciences, 68 (2013) 180189. https://dx.doi.org/10.1016/j.ijmecsci.2013.01.013

22 Liu, L., Cao, D., and Sun, S. Vibration analysis for rotating ring-stiffened cylindrical shells with arbitrary boundary conditions. Journal of Vibration and Acoustics, 135 (6) (2013) 061010. https://dx.doi.org/10.1115/1.4024220

23 Amabili, M., Arziera, R, and Negri, A. Experimental study on large-amplitude vibrations of water-filled circular cylindrical shells, Journal of fluids and structures, 16 (2) (2002) 213-227. https://dx.doi.org/10.1006/jfls.2001.0412 